\title{
Thyroid Hormonal Status in Newly Diagnosed Type 2 Diabetes Mellitus
}

\author{
${ }^{1}$ Mohammad Shameem Al Mamun , ${ }^{2}$ Nurun Nahar, ${ }^{2}$ Mohammad Simoon Salekin, ${ }^{1}$ Mohammad Mahbubur Rahman \\ ${ }^{1}$ Directorate General of Health Services, Mohakhali, Dhaka. \\ ${ }^{2}$ National Institute of Nuclear Medicine and Allied Sciences, Shahbagh, Dhaka
}

Correspondence Address : Dr. Mohammad Shameem Al Mamun, MBBS, M-Phil, Deputy Program Manager (Planning, Monitoring and Research), Directorate General of Health Services, Mohakhali, Dhaka. E mail: alshameem79@yahoo.com

\begin{abstract}
Objectives: Diabetes mellitus and thyroid dysfunction are the two most common endocrinopathies seen in general population. The study was done to determine whether there is any co-occurence of thyroid hormonal status alternating in newly diagnosed type 2 diabetes mellitus.

Patients and Methods: This Cross-sectional study which was carried out at National Institute of Nuclear Medicine and Allied Sciences and outpatient Department (OPD) of Endocrinology of Bangabandhu Sheikh Mujib Medical University, Shahbag, Dhaka during the period January 2015 to July 2016. A total of 98 newly diagnosed type 2 diabetic patients (Group I) and 98 healthy individuals (Group II) were enrolled in this study purposively. After taking written consent, history of the study subjects was taken and clinical checkup was done. Age of the subjects of both the group were 30 years and above. Glycemic status of both the group was assessed by measuring fasting blood sugar, blood sugar two hours after $\mathbf{7 5}$ gm oral glucose and blood for HbA1C. Patients with type 1 and other form of diabetes mellitus and any condition that may impair glycemic control were excluded from the study. Thyroid hormonal status of both the group was evaluated by measuring patients' serum TSH by Immunoradiometric Assay (IRMA) and serum FT3 and serum FT4 by Radioimmunoassay (RIA) method in NINMAS. All the data were digitized and analyzed using SPSS $\mathbf{- 2 2 . 0}$ software.

Results: In this study, mean age of the patients was $46.0 \pm 9.7$ years and $45.5 \pm 7.7$ years in group $I$ and group $I$ respectively. Male female ratio was 1:1.45 in group I and 1:1.08 in group II. Fasting blood sugar, blood sugar two hours after $75 \mathrm{gm}$ oral glucose and HbA1c were significantly higher in group I than that of group II. Mean TSH, FT3 and FT4 were $2.37 \pm 3.86$ $\mathrm{mIU} / \mathrm{L}, 6.35 \pm 2.41 \mathrm{pmol} / \mathrm{L}$ and $15.79 \pm 5.41 \mathrm{pmol} / \mathrm{L}$ respectively in group I whereas $2.28 \pm 2.67 \mathrm{mIU} / \mathrm{L}, 6.59 \pm 1.83 \mathrm{pmol} / \mathrm{L}$ and $16.25 \pm 3.46 \mathrm{pmol} / \mathrm{L}$ respectively in group II. But there was no statistical significant difference between group I and group II. In group I, sixteen patients had thyroid disorder (seven had hyperthyroidism and nine had hypothyroidism). In group II, five patients had thyroid disorder (two had hyperthyroidism and three had hypothyroidism). The difference was statistically
\end{abstract}

significant. Fasting blood sugar positively correlated with TSH, FT3 and FT4 in group I, similarly HbA1c correlated with TSH and FT4 but not with FT3 in group I.

Conclusion: Thyroid disorder was $16.3 \%$ in newly diagnosed type 2 diabetic patients and $5.1 \%$ in normal individuals.

Keywords: Type 2 diabetic; Thyroid disorder.

\section{INTRODUCTION}

The role of hyperthyroidism in diabetes was investigated in 1927, by Coller and Huggins proving the association of hyperthyroidism and worsening of diabetes (1). Thyroid diseases and diabetes mellitus (DM) are the two most common endocrine disorders encountered in clinical practice. Prevalence of diabetes in Bangladesh is $10 \%$ of population and in India $8 \%$ of population (2).

The World Health Organization recognizes three main form of diabetes: type 1, type 2 and gestational diabetes which have similar signs, symptoms and consequences but different causes and population distributions. Type 1 Diabetes mellitus, formerly known as childhood diabetes or juvenile diabetes, is usually due to $\mathrm{T}$ - cell mediated autoimmune destruction of pancreatic beta cells which produce insulin (3). Type 2 diabetes mellitus is a heterogeneous group of disorders characterized by variable degree of insulin resistance, impaired insulin secretion and increase glucose production (4).

Thyroid disorders are also very common in general population and it is second only to DM to affect the endocrine system (5). Thyroid hormones T3 and T4 
have significant effect on blood glucose homeostasis, involved in cellular metabolism and cause functional derangement of cell. Hypothyroidism can result in hypoglycemia and hyperthyroidism results hyperglycemia (6).

The first report showing association between diabetes and thyroid dysfunction was published in 1979 (7). Since then a number of studies have estimated the prevalence of thyroid dysfunction among diabetes patients to varying from $2.2 \%$ to $17 \%$, the most common disorders being subclinical hypothyroidism (8).

Thyroid disorders have significant effect on blood glucose levels. Studies have found that diabetes mellitus and thyroid disorders tend to co-occur in patients. Almost one third of people with type 1 diabetes have found to have thyroid disease. In type 1 diabetes thyroid dysfunction may be due to underlying genetic predisposition which leads to the coexistence of autoimmune destruction of pancreatic islets cells as well as thyrocytes (9). In type 2 diabetes mellitus, the association with thyroid dysfunction is largely unexplained, although it may relate to old age, and also possibly the fact that, some type 2 diabetes mellitus actually type 1 diabetes mellitus patients who have a very slow onset and so have the same genetic predisposition as type 1 diabetes mellitus (10). As diabetes mellitus is a major health problem, any disorders that may even be weakly associated with it, needs special attention.

\section{PATIENTS AND METHODS}

This Cross-sectional analytical study was carried out at National Institute of Nuclear Medicine and Allied Sciences (NINMAS) and OPD of Endocrinology of Bangabandhu Sheikh Mujib Medical University, Shahbag, Dhaka over a period of 19 months from January 2015 to July 2016. A total of 98 newly diagnosed type 2 diabetic patients (Group I) and 98 healthy individuals (Group II) were enrolled in this study purposively. After taking written consent, history of the study subjects was taken and clinical checkup was done. Age of the subjects of both the group were 30 years and above. Glycemic status of both the group was assessed by measuring fasting blood sugar, blood sugar two hours after 75 gm oral glucose (2 HA 75 GO) and blood for HbA1C. Patients with type 1 and other form of diabetes mellitus and any condition that may impair glycemic control were excluded from the study. Thyroid hormonal status of both the group was evaluated by measuring patient's serum TSH by Immunoradiometric Assay (IRMA) and serum FT3 and serum FT4 by Radioimmunoassay (RIA) method in NINMAS. All the data were digitized and analyzed using SPSS - 22.0. Quantitative data were expressed as mean and standard deviation and qualitative data were expressed as frequency distribution and percentage. Association between categorical variables was analyzed by chi-squared test and continuous variable by independent sample t-test. Correlation was done by Pearson correlation coefficient test, as for normal distribution. Normality of distribution was seen by Shiparo-Wilk test. For all statistical tests, $\mathrm{p}$ value $<0.05$ was considered as statistically significant.

\section{RESULTS}

Table 1 shows that, mean age of the patients were 46.0 \pm 9.7 years and $45.5 \pm 7.7$ years in group I and group II respectively. There was no significant difference between two groups. In both groups, female were predominant. In group I, 58 (59.2\%) and 40 (40.8\%) study populations were female and male respectively, similarly in group II, $51(52.0 \%)$ and 47 (48.0\%) study populations were female and male respectively. Both systolic and diastolic BP were significantly higher in group I than that of group II but there was no significant difference in pulse and BMI between two groups (Table 2). Fasting blood sugar, blood sugar $2 \mathrm{HA} 75 \mathrm{GO}$ and $\mathrm{HbA} 1 \mathrm{c}$ were significantly higher in group I than that of group II (Table 3). From Table 4, it is found that mean TSH, FT3 and FT4 were $2.37 \pm$ $3.86 \mathrm{mIU} / \mathrm{L}, 6.35 \pm 2.41 \mathrm{pmol} / \mathrm{L}$ and $15.79 \pm 5.41$ $\mathrm{pmol} / \mathrm{L}$ respectively in group I whereas $2.28 \pm 2.67$ $\mathrm{mIU} / \mathrm{L}, 6.59 \pm 1.83 \mathrm{pmol} / \mathrm{L}$ and $16.25 \pm 3.46 \mathrm{pmol} / \mathrm{L}$ respectively in group II (Table 4). But there was no 
statistical significant difference between group I and group II. Table 5 shows that, seven (7.1\%) and two (2.0\%) patients had hyperthyroidism in group I and group II respectively. On the other hand nine (9.2\%) and three $(3.1 \%)$ patients had hypothyroidism in group I and group II. There was statistically significant difference between group I and group II in respect to thyroid disorders present or absent. Table 6 shows that fasting blood sugar positively correlated with TSH,

FT3 and FT4 in type 2 diabetic patients and HbA1c correlated with TSH and FT4 but not with FT3.

Table 1: Distribution of patients according to age in group I and group II $(n=196)$

\begin{tabular}{|c|c|c|c|}
\hline \multirow[b]{2}{*}{ Age (years) } & \multicolumn{2}{|l|}{ Group } & \multirow[b]{2}{*}{ P value } \\
\hline & $\begin{array}{l}\text { Group I } \\
\text { (Type 2 diabetic } \\
\text { patients) }\end{array}$ & $\begin{array}{l}\text { Group II } \\
\text { (Healthy subjects) }\end{array}$ & \\
\hline Age in year $($ Mean \pm SD) & $46.0 \pm 9.7$ & $45.5 \pm 7.7$ & 0.726 \\
\hline \multicolumn{4}{|l|}{ Gender } \\
\hline Male & $40(40.8)$ & $47(48.0)$ & 0.314 \\
\hline Female & $58(59.2)$ & $51(52.0)$ & \\
\hline
\end{tabular}

Unpaired $t$ test was done to measure the level of significance in case of age and Chi-square test was done in case of gender to measure the level of significance.

Table 2: Distribution of patients according to clinical findings in group I and group II $(n=196)$

\begin{tabular}{l|ll|l}
\hline \multirow{2}{*}{ Clinical findings } & Group & \multirow{2}{*}{ P value } \\
\cline { 2 - 3 } & $\begin{array}{l}\text { Group I } \\
\text { (Type 2 diabetic } \\
\text { patients) }\end{array}$ & $\begin{array}{l}\text { Group II } \\
\text { (Healthy subjects) }\end{array}$ & \\
\hline Pulse (min) & $80.8 \pm 7.5$ & $79.2 \pm 5.6$ & 0.085 \\
\hline Systolic BP $(\mathrm{mmHg})$ & $133.9 \pm 13.9$ & $127.5 \pm 11.9$ & 0.001 \\
\hline Diastolic BP $(\mathrm{mmHg})$ & $81.6 \pm 8.0$ & $78.8 \pm 8.2$ & 0.014 \\
\hline $\mathrm{BMI}(\mathrm{Kg} / \mathrm{m} 2)$ & $24.3 \pm 2.6$ & $24.6 \pm 2.4$ & 0.449 \\
\hline
\end{tabular}

Unpaired t test was done to measure the level of significance.

Table 3: Glycemic findings in group I and group II $(n=196)$

\begin{tabular}{l|ll|l}
\hline \multirow{2}{*}{ Glycemic findings } & Group & & \\
\cline { 2 - 3 } & $\begin{array}{l}\text { Group I } \\
\text { (Type 2 diabetic } \\
\text { patients) }\end{array}$ & $\begin{array}{l}\text { Group II } \\
\text { (Healthy } \\
\text { subjects) }\end{array}$ & P value \\
\hline FBS (mmol/L) & $10.17 \pm 1.84$ & $5.43 \pm 0.57$ & $<0.001$ \\
\hline $\begin{array}{l}\text { 2hrs after 75 gms oral glucose } \\
\text { solutions (mmol/L) }\end{array}$ & $16.12 \pm 2.32$ & $7.97 \pm 0.87$ & $<0.001$ \\
\hline HbAlc (\%) & $10.11 \pm 1.08$ & $5.52 \pm 0.52$ & $<0.001$ \\
\hline
\end{tabular}

Unpaired $t$ test was done to measure the level of significance.
Table 4: Distribution of patients according to thyroid hormone findings in group I and group II $(n=196)$

\begin{tabular}{|c|c|c|c|}
\hline \multirow[b]{2}{*}{ Thyroid hormones } & \multicolumn{2}{|l|}{ Group } & \multirow[b]{2}{*}{ P value } \\
\hline & $\begin{array}{l}\text { Group I } \\
\text { (Type 2 diabetic } \\
\text { patients) }\end{array}$ & $\begin{array}{l}\text { Group II } \\
\text { (Healthy subjects) }\end{array}$ & \\
\hline $\mathrm{TSH}(\mathrm{mIU} / \mathrm{L})$ & $2.37 \pm 3.86$ & $2.28 \pm 2.67$ & 0.859 \\
\hline $\mathrm{FT}_{3}(\mathrm{pmol} / \mathrm{L})$ & $6.35 \pm 2.41$ & $6.59 \pm 1.83$ & 0.434 \\
\hline $\mathrm{FT}_{4}(\mathrm{pmol} / \mathrm{L})$ & $15.79 \pm 5.41$ & $16.25 \pm 3.46$ & 0.482 \\
\hline
\end{tabular}

Unpaired t test was done to measure the level of significance.

Table 5: Distribution of patients according to thyroid disorder in group I and group II ( $n=196)$

\begin{tabular}{|c|c|c|c|}
\hline \multirow[b]{2}{*}{ Thyroid disorder } & \multicolumn{2}{|l|}{ Group } & \multirow[b]{2}{*}{$P$ value } \\
\hline & $\begin{array}{l}\text { Group I } \\
\text { (Type 2 diabetic } \\
\text { patients) }\end{array}$ & $\begin{array}{l}\text { Group II } \\
\text { (Healthy } \\
\text { subjects) }\end{array}$ & \\
\hline Normal & $82(83.7)$ & $93(94.9)$ & \multirow[t]{4}{*}{0.039} \\
\hline Hyperthyroidism $(\mathrm{TSH}<0.3 \mathrm{mIU} / \mathrm{L})$ & $7(7.1)$ & $2(2.0)$ & \\
\hline Hypothyroidism $(\mathrm{TSH}>5.0 \mathrm{mIU} / \mathrm{L})$ & $9(9.2)$ & $3(3.1)$ & \\
\hline Total & $98(100.0)$ & $98(100.0)$ & \\
\hline
\end{tabular}

Chi-square test was done to measure the level of significance.

Table 6: Correlation of FBS and HbA1c with TSH, FT3 and FT4 in type 2 diabetic patients $(n=98)$

\begin{tabular}{|l|l|l|l|l|}
\hline \multirow{2}{*}{ Parameters } & \multicolumn{3}{|l|}{ Fasting blood sugar } & HbA1c \\
\cline { 2 - 5 } & r value & p value & r value & p value \\
\hline $\mathrm{TSH}(\mathrm{mIU} / \mathrm{L})$ & 0.396 & $<0.001$ & 0.253 & 0.013 \\
\hline $\mathrm{FT}_{3}(\mathrm{pmol} / \mathrm{L})$ & 0.221 & 0.031 & 0.151 & 0.142 \\
\hline $\mathrm{FT}_{4}(\mathrm{pmol} / \mathrm{L})$ & 0.313 & 0.002 & 0.294 & 0.004 \\
\hline
\end{tabular}

Pearson correlation coefficient test was done for normal distribution.

\section{DISCUSSION}

In this study, mean age of the patients were $46.0 \pm 9.7$ years and $45.5 \pm 7.7$ years in group I and Group II respectively. There was no significant difference between group I and group II. In both groups, female were predominant. In a similar study, Vinu et al. (5) have taken same number of male and female in case and control group and the mean age was slightly lower than this study. In another study, mean age of diabetic subject $43.16 \pm 5.06$ years and non-diabetic subjects $45.37 \pm 6.19$ years $(11)$ which were almost similar to the present study. Both systolic and diastolic BP was significantly higher in group I than that of group II but 
there was no significant difference in pulse and BMI between two groups.

Mean FBS $(10.17 \pm 1.84 \mathrm{mmol} / \mathrm{L}$ and $5.43 \pm 0.57$ $\mathrm{mmol} / \mathrm{L}$ in group I and group II respectively) and mean blood sugar 2HA75GO $(16.12 \pm 2.32 \mathrm{mmol} / \mathrm{L}$ and 7.97 $\pm 0.87 \mathrm{mmol} / \mathrm{L}$ in group I and group II respectively) are higher in this study both in diabetic and nondiabetic individuals than the study conducted by Saha et al. ( FBS $8.24 \pm 2.58 \mathrm{mmol} / \mathrm{L}$ in diabetic subjects and $5.16 \pm 0.80 \mathrm{mmol} / \mathrm{L}$ in non-diabetic subjects and blood sugar 2HA $75 \mathrm{GO} 12.86 \pm 5.25 \mathrm{mmol} / \mathrm{L}$ and 6.51 $\pm 0.95 \mathrm{mmol} / \mathrm{L}$ in diabetic and non-diabetic subjects respectively) (6). HbA1c (10.11

$\pm 1.08) \%$ and $(5.52 \pm 0.52) \%$ in group I and group II respectively is higher in this study both in diabetic and non-diabetic individuals than the study conducted by Vikhe et al. $(7.38 \pm 0.72 \%$ and $5.12 \pm 0.21$ in diabetic and non-diabetic subjects respectively (11). Saha et al.

(6) found $\mathrm{HbA} 1 \mathrm{C}$ in diabetic and non-diabetic

subjects are almost same as present study.

In this study, mean TSH was slightly higher and mean FT3 and FT4 were slightly lower in group I than in group II. But there was no statistical significant difference. These findings partially agreed with the study conducted by Islam et al. (12) where they showed that the level of FT3 was significantly lower in type 2 diabetics when compared with the healthy subjects but FT4 and S.TSH did not show any statistically significant difference between type 2 diabetics and healthy individuals. Raghuwanshi et al. (13) found significant higher TSH and significantly lower $\mathrm{T} 3$ and $\mathrm{T} 4$ in diabetic type 2 patients comparing healthy individuals and agreed with report of Alam et al. (14).

In this study, Out of 98 type 2 diabetic patients, 16 (16.3\%) showed thyroid disorder $(7.1 \%$ had hyperthyroidism and $9.2 \%$ had hypothyroidism) and out of 98 normal healthy individuals five $(5.1 \%)$ showed thyroid disorder (2.0\% had hyperthyroidism and $3.1 \%$ had hypothyroidism). There was statistically significant difference between group I and group II $(\mathrm{p}=0.039)$. These findings agree with the report of Vinu et al. (5) and
Alam et al. (14). The prevalence of thyroid dysfunction among diabetes patients varies from 2.2 to $17.0 \%$, the most common disorder being subclinical hypothyroidism

(8). However, few studies have also estimated much higher prevalence of thyroid dysfunction in diabetes i.e. $31 \%$ and $46.5 \%$ respectively (15).

In this study, fasting blood sugar positively correlated with TSH, FT 3 and FT4 in diabetic patients. Similarly, HbA1c correlated with TSH and FT4 but not with FT3 .In a study by Raghuwansi et al. (13), fasting plasma glucose (FPG) positively correlated with TSH and T3. Alam et al. (14) found significant correlation of FBS with TSH and FT3 in type 2 diabetic patients but did not find any correlation of FBS with FT4.

\section{CONCLUSION}

This study shows higher incidence of thyroid disorder in type 2 diabetic patients (16.3\%) comparing non diabetic healthy individuals $(5.1 \%)$ and fasting blood sugar has positive correlation with TSH, FT3 and FT4. Similarly HbA1c has positive correlation with TSH and FT4 but not with FT3.

\section{REFERENCES}

1. Coller FA, Huggins CB. Effect of hyperthyroidism upon diabetes mellitus: striking improvement in diabetes mellitus from thyroidectomy. Annals of Surgery 1927;86(6):877.

2. IDF Diabetes Atlas, Sixth edition, 2013

3. Definition, diagnosis and classification of diabetes mellitus and its complications: report of a WHO consultation. Part 1, Diagnosis and classification of diabetes mellitus. World Health Organization. Dept. of Noncommunicable Disease Surveillance. retrieved at 1999, 17 July 2016, < ttp://apps.who.int/iris/bitstream/10665/66040/1/WHO_NCD_NCS_99.2.pdf

4. Rother KI. Diabetes treatment — bridging the divide. The New England Journal of Medicine 2007;356(15):1499.

5. Vinu V, Chitnis P, Gupta VK. Evaluation of thyroid dysfunction among type 2 diabetic patients. International Journal of Pharmacy and Biological Sciences 2012;2(4):151.

6. Saha HR, Khan H, Sarkar BC, Khan SA, Sana NK, Sugawara A, Choudhury S. A Comparative Study of Thyroid Hormone and Lipid Status of Patient with and without Diabetes in Adults. Open Journal of Endocrine and Metabolic Diseases. 2013 May 23;3(02):113.

7. Perros P, Mc Crimmon RJ, Shaw G, Frier BM. Frequency of thyroid dysfunction in diabetic patients: value of annual screening. Diabetic Medicine 1995;12(7):622-7.

8. Papazafiropoulou A, Sotiropoulos A, Kokolaki A, Kardara M, Stamataki P, Pappas S. Prevalence of thyroid dysfunction among greek type 2 
diabetic patients attending an outpatient clinic. Journal of Clinical Medicine Research 2010;2(2):75-8.

9. American Diabetes Association. Screening for diabetes. Diabetes Care. 2002;25(1):S12-S24.

10. Abrams JJ, Grundy SM. Cholesterol metabolism in hypothyroidism and hyperthyroidism in man. Journal of Lipid Research 1981;22(2):323-38.

11. Vikhe VB, Kanitkar SA, Tamakuwala KK, Gaikwad AN, Kalyan M, Agarwal RR. Thyroid dysfunction in patients with type 2 diabetes mellitus at tertiary care centre. National Journal of Medical Research 2013;3(4):377-80.

12. Islam S, Yesmine S, Khan SA, Alam NH. and Islam, S. A comparative study of thyroid hormone levels in diabetic and non-diabetic patients. The
Southeast Asian Journal of Tropical Medicine and Public Health 2008; 39(5): 913-6

13. Raghuwanshi PK, Rajput DP, Ratre BK, Jain R, Patel N, Jain S. Evaluation of thyroid dysfunction among type 2 diabetic patients. Asian Journal of Medical Sciences 2014;6(3):33-7.

14. Alam MJ, Mukti MNM, Hoque MM, Ali MI, Kamal MM, Mallik SC. et al., Cross sectional evaluation of thyroid hormone levels in non-diabetic and diabetic patients in Bangladeshi population. Asian Journal of Biological Science 2013; 6(4):228-233.

15. Kordonouri O, Charpentier N. and Hartmann R. GADA positivity at onset of type 1 diabetes is a risk factor for the development of autoimmune thyroiditis. Pediatric Diabetes 2011;12(1):31-33. 